E3S Web of Conferences 1, 33008 (2013)

DOI: $10.1051 / \mathrm{e} 3 \operatorname{sconf} / 20130133008$

C) Owned by the authors, published by EDP Sciences, 2013

\title{
Leaching of heavy metals from dredged bottom sediments
}

\author{
A. $\operatorname{Baran}^{1}$ and M. Tarnawski ${ }^{2}$ \\ ${ }^{1}$ Department of Agricultural and Environmental Chemistry, University of Agriculture in Krakow, al. A. Mickiewicza 21, \\ 31-120 Krakow, POLAND, Agnieszka.Baran@ur.krakow.pl \\ ${ }^{2}$ Department of Water Engineering 2 , University of Agriculture in Krakow, al. A. Mickiewicza 24/28, 30-059 Kraków, \\ POLAND,rmtarnaw@cyf-kr.edu.pl
}

\begin{abstract}
Deposition of sediments on land in atmospheric conditions causes many risks connected with environmental protection. Particularly dangerous is leaching of heavy metals from sediments deposited on land The research aimed at assessment of leaching of heavy metals from dredged bottom sediments potentially disposed on land. In this research it has been shown that the leaching of heavy metals during disposal of polluted and unpolluted bottom sediments does not pose threat to the environment. Leaching of the studied metals in relation to their total content in bottom sediments varied from 1 to 5.5.\% for $\mathrm{Zn}$, from 0.9 to $9.4 \%$ for $\mathrm{Cu}$, from 3.3 to $4.5 \%$ for $\mathrm{Ni}$, from 1.6. to $6.9 \%$ for $\mathrm{Pb}$, from 0.9 to $19.2 \%$ for $\mathrm{Cd}$ and from 0.8 to $6.3 . \%$ for $\mathrm{Cr}$. Considering their final destination, the potential and actual environmental hazard which the extracted bottom deposits pose should be assessed by determining the leachability of the heavy metals.
\end{abstract}

Key words: heavy metals, leaching, deposition, dredged sediments

\section{Introduction}

Deepening of water reservoir is commonly used and allows to keep them in proper condition so that they fulfil their economic functions. According to the data from the Sed-Net monitoring program, approximately 100-200 . $10^{6} \mathrm{~m}^{3}$ of sediments are produced in Europe each year. In comparison, in the United States $400 \cdot 10^{6} \mathrm{~m}^{3}$ of sediments are produced each year. Deposition of sediments on land in atmospheric conditions causes many risks connected with environmental protection. Particularly dangerous is leaching of harmful substances (including heavy metals) from sediments deposited on land, which in consequence may lead to pollution of surface waters, underground waters and soils. From ecological reasons, mobility of heavy metals leaching of waste, expressed by susceptibility to being washed out of matrix, is the most important feature of waste (apart from its composition) taken into account in the assessment of its harmfulness to the environment. In order to assess the noxiousness of various wastes, examinations of chemical composition of water extracts are conducted.

The research aimed at assessment of leaching of heavy metals from dredged bottom sediments potentially disposed on land.

\section{Materials and Methods}

Bottom sediments from three water reservoirs, that is the Rzeszow Reservoir (Podkarpackie province), reservoir in Narozniki (Malopolskie province) and the Rybnik Reservoir (Slaskie province) were used in the research. Sediment samples were taken from all the reservoirs, according to the following methodology. Three zones were established in a reservoir bowl: inlet (backwater), middle and outlet (near the dam) zone. 5-6 samples were taken from each zone and mixed in order to average the properties of sediments in samples representative of a given zone. Ekman sampler was used for obtaining sediment samples. Leaching of metals from bottom sediments was conducted in compliance with Polish Standard PN-Z-15009, 1997 Solid wastes. Preparation of water extracts. $10 \mathrm{~g}$ of the sediments was weighed out. The sample was put into a conical flask and $100 \mathrm{~cm}^{3}$ of distilled water was added. After $1 \mathrm{~h}$, the flask was corked and shaken for $4 \mathrm{~h}$. Then, the flask was opened and left for $16 \mathrm{~h}$. Subsequently, the flask was shaken again for 4 $h$. After being centrifuged, the eluate was transferred into a $50 \mathrm{~cm}^{3}$ measuring flask. The sediment was treated with another identical portion of distilled water and washed again. The procedure was repeated so in total three water extracts were obtained. Total contents of heavy metals in the sediments were assessed after hot mineralization in a mixtured of $\mathrm{HNO}_{2}$ and $\mathrm{HClO}_{3}$ acids (3:2). Concentrations 
of metals ( $\mathrm{Zn}, \mathrm{Cu}, \mathrm{Ni}, \mathrm{Cd}, \mathrm{Pb}, \mathrm{Cr})$ in the obtained extracts and solutions were determined with an ICP-OES spectrometer (Pekin Elmer Optima 7300 DV). Correctness of the carried out analyses was verified using reference material CRM016-050.

\section{Results and Discussion}

The results obtained using the water extract method do not reflect the total content of a given component in wastes, which could be mobilised in the environment. However, the results allow to obtain a rough assessment of a potential threat posed by waste material. Contents of metals determined in water extracts prepared from sediments are presented in table 1 . Zinc content in the examined water extracts was from 2.59 to $8.83 \mathrm{mg}$; copper from 0.48 to $2.67 \mathrm{mg}$; nickel from 0.65 to 1.38 $\mathrm{mg}$; lead from 0.58 to $1.35 \mathrm{mg}$; cadmium from 0.03 to $0.86 \mathrm{mg}$ and chromium from 0.94 to $1.28 \mathrm{mg} \cdot \mathrm{kg}^{-1}$. The highest mean content of zinc, copper and lead was determined in water extracts prepared from the bottom sediment from Rybnik, whereas the highest mean content of nickel, chromium and cadmium was determined in water extracts from sediment from Rzeszów. Water extracts from the bottom sediment from Narozniki generally showed the lowest content of the studied metals (Tab. 1). The rate of leaching (coefficient) is an important parameter which tells us about a potential threat connected with deposition of bottom sediments in land environment (Prokop et al. 2003). This coefficient informs about the amount and rate of leaching a given element from the bottom sediment. The rate of leaching metals from bottom sediments was calculated as a ratio of the content of an element in a eluate to its total content in the bottom sediment (Tab. 1). The rate of leaching in the presented research had the following values: from 0.01 to 0.06 for zinc; from 0.01 to 0.09 for copper; from 0.033 to 0.045 for nickel; from 0.02 to 0.07 for lead; from 0.01 to 0.19 for cadmium and from 0.01 to 0.06 for chromium (Tab. 1). The presented data indicate that the highest amount of $\mathrm{Zn}, \mathrm{Cu}, \mathrm{Ni}, \mathrm{Pb}$ and $\mathrm{Cr}$ will be released to the environment from the bottom sediment of the reservoir in Narozniki, whereas the highest amount of $\mathrm{Cd}$ will be released from the bottom sediment of the Rzeszow Reservoir because the rate of leaching metals from these sediments had the highest values (tab. 1). The lowest values of the rate of leaching coefficient of metals were obtained for the bottom sediment from Rybnik. Intermediate values for $\mathrm{Zn}, \mathrm{Cu}, \mathrm{Ni}, \mathrm{Pb}$ and $\mathrm{Cr}$ were set for bottom sediments of the Rzeszow Reservoir. Low solubility of heavy metals in the bottom sediments of the Rybnik and Rzeszow reservoirs is connected with a low concentration of hydrogen ions $(\mathrm{pH})$ in these sediments, amounting respectively to 6.3 . and 7.3 , as well as with a high content of organic matter, particularly in the Rybnik Reservoir, amounting to $26.5 \%$ (Rybnik) and $6.7 \%$ (Rzeszow).

In this research it has been shown that the leaching of heavy metals during disposal of polluted (Rybnik, Rzeszow) and unpolluted (Narozniki) bottom sediments does not pose threat to the environment. Leaching of the studied metals in relation to their total content in bottom sediments varied from 1 to $5.5 \%$ for $\mathrm{Zn}$, from 0.9 to $9.4 \%$ for $\mathrm{Cu}$, from 3.3 to $4.5 \%$ for $\mathrm{Ni}$, from 1.6 . to $6.9 \%$ for $\mathrm{Pb}$, from 0.9 to $19.2 \%$ for $\mathrm{Cd}$ and from 0.8 to $6.3 . \%$ for $\mathrm{Cr}$. It may mean that approximately $97 \%$ of $\mathrm{Zn}, 94 \%$ of $\mathrm{Cu}, 96 \%$ of $\mathrm{Ni}, 95 \%$ of $\mathrm{Pb}, 90 \%$ of $\mathrm{Cd}$ and $96 \%$ of $\mathrm{Cr}$ are connected with the organic or residual fraction. Releasing of most heavy metals from bottom sediments during their disposal will be the highest for bottom

Table 1. The content of heavy metals in water extracts and bottom sediments, and their rate of leaching

\begin{tabular}{|c|c|c|c|c|}
\hline \multirow[t]{2}{*}{ Metal } & \multirow{2}{*}{$\begin{array}{c}\text { Bottom } \\
\text { sediment }\end{array}$} & \multicolumn{2}{|c|}{ Content $\left[\mathrm{mg} \cdot \mathrm{kg}^{-1}\right]$} & \multirow{2}{*}{ Rate of leaching } \\
\hline & & In water extracts & Total & \\
\hline \multirow{3}{*}{$\mathrm{Zn}$} & Rzeszów & 2.59 & 106.7 & 0.02 \\
\hline & Rybnik & 8.83 & 902.3 & 0.01 \\
\hline & Narożniki & 2.67 & 48.19 & 0.06 \\
\hline \multirow{3}{*}{$\mathrm{Cu}$} & Rzeszów & 1.87 & 22,87 & 0.08 \\
\hline & Rybnik & 2.67 & 286.2 & 0.01 \\
\hline & Narozniki & 0.48 & 5.13 & 0.09 \\
\hline \multirow{3}{*}{$\mathrm{Ni}$} & Rzeszów & 1.38 & 35.20 & 0.04 \\
\hline & Rybnik & 1.30 & 39.95 & 0.03 \\
\hline & Narozniki & 0.65 & 14.50 & 0.04 \\
\hline \multirow{3}{*}{$\mathrm{Pb}$} & Rzeszów & 1.28 & 19.63 & 0.07 \\
\hline & Rybnik & 1.35 & 84.45 & 0.02 \\
\hline & Narozniki & 0.58 & 8.40 & 0.07 \\
\hline \multirow{3}{*}{$\mathrm{Cd}$} & Rzeszów & 0.86 & 4.47 & 0.19 \\
\hline & Rybnik & 0.07 & 7.53 & 0.01 \\
\hline & Narozniki & 0.03 & 0.35 & 0.09 \\
\hline \multirow{3}{*}{$\mathrm{Cr}$} & Rzeszów & 1.28 & 35.09 & 0.04 \\
\hline & Rybnik & 0.94 & 125.21 & 0.01 \\
\hline & Narozniki & 1.24 & 19.60 & 0.06 \\
\hline
\end{tabular}


sediments of the reservoir in Narozniki, lower for bottom sediments of the Rzeszow Reservoir, and the lowest for bottom sediments of the Rybnik Reservoir. Only in the case of cadmium, a potentially high risk connected with leaching of this metal during disposal of dredged bottom sediments of zone 1 of the Rzeszow Reservoir may occur.

\section{Conclusion}

1. The studies showed that during storage on land the biggest amount of heavy metals will be released from the Narozniki reservoir bottom sediments, less for Rzeszow reservoir bottom sediments, and the smallest for a Rybnik reservoir bottom sediments. The rate of metal leaching from the sediments for: $\mathrm{Zn}, \mathrm{Cu}, \mathrm{Pb}, \mathrm{Ni}, \mathrm{Cr}$ : Narozniki > Rzeszów > Rybnik, Cd: Rzeszów > Narozniki > Rybnik. 2. In these studies, relatively high mobility of metals from Narozniki bottom sediments, despite the low total content of metals depended on the physico-chemical properties of these sediments. These bottom sediemnts were characterized by reactivity slightly acidic, sand granulometric composition (86\% sand) and low organic carbon content averaging $0.76 \%$.

3. Considering their final destination, the potential and actual environmental hazard which the extracted bottom deposits pose should be assessed by determining the leachability of the heavy metals.

\section{References}

Prokop Z., Nangheluwe M.L., Van Sprang P.A., Janssen C.R., Holoubek I. Mobility and toxicity of metals in sandy sediments deposited on land. Ecotoxicol., Environ. Saf., 2003; 54: 65-73.

\section{Acknowledgements}

Scientific work financed the budget for science Research Grant No. N N305 295037 "Assestement of the possibility of agricultural use reservoir bottom sediments" (2009-2012). 